\title{
PENGARUH BUKU MANAJEMEN ARSIP PERGURUAN TINGGI TERHADAP HASIL BELAJAR KEARSIPAN MAHASISWA ADMINISTRASI PERKANTORAN
}

\author{
Sri Mutmainnah, Ellys Siregar, Gartima Sitanggang \\ Fakultas Ekonomi Universitas Negeri Medan, Indonesia \\ mutmainnah.sri@gmail.com, ellyssiregaradp@gmail.com,gartimasitanggang1960@gmail.com
}

\begin{abstract}
Abstrak: Pengaruh Buku Manajemen Arsip Perguruan Tinggi terhadap Hasil Belajar Kearsipan Mahasiswa Administrasi Perkantoran. Peningkatan hasil belajar Mata Kuliah Kearsipan mahasiswa Administrasi Perkantoran, Fakultas Ekonomi, Universitas Negeri Medan menjadi sasaran utama dari penelitian ini. Penelitian ini merupakan kelanjutan dari penelitian sebelumnya tentang pengembangan buku Manajemen Arsip Perguruan Tinggi. Metode eksperimen kuasi digunakan untuk melihat dampak dari pengembangan buku Manajemen Arsip Perguruan Tinggi terhadap hasil belajar mahasiswa pada Mata Kuliah Kerasipan. Mahasiswa Program Studi Administrasi Perkantoran yang mengikuti mata kuliah Manajemen Kearsipan berjumlah 31 orang merupakan sampel dalam penelitian ini. Uji-t dilakukan untuk menganalisis dua kelompok dari data satu kelompok sampel berpasangan melalui perbandingkan data sebelum (pretest) dengan sesudah (post test) perlakuan dari satu kelompok sampel. Hasil penelitian menunjukkan bahwa penggunaan Buku Manajemen Arsip Perguruan Tinggi memberikan efek terhadap hasil belajar kearsipan Mahasiswa Administrasi Perkantoran, Jurusan Ekonomi, Fakultas Ekonomi, Universitas Negeri Medan. Buku teks yang mengandung konsep dan prosedur pengelolaan arsip aktif dan inaktif serta klasifikasi dan jadwal retensi arsip akan membantu mahasiswa untuk menguasai konsep pengeloaan arsip aktif dan inaktif dengan lebih mudah.
\end{abstract}

Kata kunci: Manajemen Arsip, Kompetensi Kearsipan

\begin{abstract}
The Influence of College Archives Management Book on Learning Outcomes of Student Archiving of Office Administration. The goal of this research is to improve the learning outcomes of Students Archiving of the Office Administration of Faculty of Economics, Universitas Negeri Medan. This research is a further research of previous research on the development of Archive Management Book for Higher Education Student. Quasi experimental method is used to see the impact of the development of Archive Management book for Higher Education Student on student learning outcomes in Archive Management Subject. 31 Office Administration students who took Archive Management were selected to be the sample in this study. T-test is used to analyze two groups of data from one paired sample group by comparing the data before and after the treatment of one sample group. The results showed that the use of the Archives Management book for Higher Education Student affected the learning outcomes of the Archive Management Course for Office Administration students at the Faculty of Economics, Universitas Negeri Medan.
\end{abstract}

Keywords: Archive Management, Archiving Competence

\section{PENDAHULUAN}

Perguruan Tinggi merupakan sarana pendidikan untuk mempersiapkan peserta didik menghadapi dunia kerja dengan memberi bekal kemampuan akademis dan profesional. Aktivitas pembelajaran yang diselenggarakan perguruan tinggi dirancang untuk menghasilkan peserta didik sebagai sumber daya manusia yang nantinya diharapkan memiliki kompetensi dan daya saing di dunia kerja. Bertentangan dengan tujuan perguruan tinggi, data statistik dari Kementerian Riset, 
Teknologi, dan Pendidikan Tinggi justru menunjukkan bahwa sarjana adalah salah satu penyumbang angka pengangguran sebesar 8,8\% dari 7 juta pengangguran di Indonesia. Lebih lanjut, data per Agustus 2019 dari Badan Pusat Statistik (BPS) menunjukkan bahwa pengangguran yang berasal dari lulusan universitas mencapai angka 5,67\% dari seluruh angkatan kerja. Diperkirakan angka tersebut mencapai 13 juta orang. Data statistik dari Kementerian Riset, Teknologi, dan Pendidikan Tinggi dan Badan Pusat Statistik (BPS) tersebut menunjukkan bahwa terdapat suatu permasalahan yang dihadapi oleh pencari kerja yang berasal dari lulusan universitas. Masalah yang dihadapi salah satunya adalah kurangnya kompetensi yang dimiliki oleh lulusan sarjana universitas. Kurangnya kompetensi tersebut merupakan hasil dari sistem pendidikan yang terlalu teoritis, sehingga kemampuan yang seharusnya dimiliki saat memasuki dunia kerja belum dapat dikuasai.

Kegiatan pembelajaran dapat dijadikan sebagai usaha dalam mengembangkan kompetensi sumber daya manusia. Tumpuan utama dari kegiatan pembelajaran di dalam kelas adalah dosen. Namun, perlu diketahui bahwa selain dosen, buku teks juga berperan penting dalam pembelajaran sebagai sumber belajar bagi peserta didik dan sumber ajar bagi dosen. Selain itu, buku teks juga dipergunakan sebagai media instruksional dalam proses pembelajaran.

Mata kuliah kearsipan adalah mata kuliah yang dirancang agar mahasiswa memiliki kompetensi untuk mengelola arsip dinamis, meliputi arsip aktif dan inaktif sebagai hasil dari kegiatan organisasi. Terdapat dua instrumen pokok dalam pengelolaan arsip yang harus selalu ada dan menjadi kaidah dalam pengelolaan arsip di setiap instansi pemerintah maupun swasta. Instrumen dan kaidah tersebut meliputi: (1) Tata Naskah Dinas, (2) Klasifikasi Arsip (KA), (3) Jadwal Retensi Arsip, dan (4) Sistem Klasifikasi Keamanan dan Akses Arsip (Suprastiwi, Chandrayanti, Azmi, Agustiani, dan Widayanti, 2016). Oleh karena itu, agar hasil belajar mata kuliah kearsipan meningkat, digunakan buku teks yang dilengkapi dengan perangkat utama pengelolaan arsip (daftar klasifikasi arsip dan jadwal retensi arsip) untuk dijadikan sumber belajar dan panduan melakukan pengelolalan arsip.

Arsip adalah himpunan fakta dan data yang dimanfaatkan untuk membantu dalam pembuatan keputusan dan alat pengawasan berasal dari catatan aktivitas dan kejadian dengan bermacam wujud dan format yang dikembangkan dengan teknologi informasi dan diciptakan serta diterima oleh lembaga pemerintah ataupun swasta (Riasmiati, 2016; Setyawan, 2016). Menurut Undang- 
Undang No 43 Tahun 2009, arsip dapat diartikan sebagai kumpulan tulisan-tulisan yang mempunyai tiga ciri-ciri utama, yaitu disimpan secara teratur dan sistematis, bernilai guna, serta mudah ditemukan kembali dengan tepat. Lebih lanjut, Suprastiwi dkk (2016) mengatakan bahwa arsip dianggap sebagai pusat ingatan dalam pengambilan kebuputusan secara cepat dan tepat mengenai suatu (Suprastiwi et al., 2016). Sedangkan kearsipan (filling), dapat diartikan sebagai suatu aktivitas menyusun file yang diawali dengan membentuk, menerima, mendokumentasikan, dan menyimpan. Oleh karena itu, manajemen arsip dapat juga diartikan sebagai kegiatan pengelolaan arsip sejak arsip diciptakan, disipan berdasarkan filling system tertentu, dirawat, ditemukan kembali ketika dibutuhkan, serta melakukan pemusnahan pada dokumen yang telah memasuki masa retensi.

Belajar pada prinsipnya adalah sebuah kegiatan berkesinambungan dan terus-menerus yang outputnya dicirikan dengan terjadinya transformasi individu. Slameto (2010) mengatakan bahwa belajar ialah sebuah upaya yang dijalankan oleh individu dengan harapan agar mendapatkan transformasi sikap dan tabiat secara utuh yang merupakan hasil dari diperolehnya suatu pengalaman dalam berinteraksi dengan lingkungan. Transformasi pada individu yang dimaksud sebagai output dari proses belajar adalah dengan adanya metamorfosis seperti adanya peningkatan dalam ilmu, wawasan, tabiat, kemahiran, keahlian, kompetensi, serta metamorfosis pada dimensidimensi lainnya (Trianto, 2013). Rusman (2014) mengatakan bahwa belajar juga dimaknai sebagai upaya berkesinambungan yang dipusatkan pada target dan keterlibatan melalui pengalaman. Belajar ialah sebuah upaya terus-menerus yang menghasilkan keterampilan, pengetahuan, sikap, dan nilai-nilai. Menurut Suyono (2011), belajar adalah kegiatan atau cara untuk mengembangkan wawasan, meningkatkan kompetensi, memperbaiki sikap, dan menguatkan keepribadian. Dapat ditarik kesimpulan bahwa belajar merupakan upaya yang dilakukan oleh individu guna mencapai metamorfosis sikap dan tindak-tanduk yang dapat ditandai dengan adanya peningkatan pengetahuan serta aspek-aspek lain dalam kehidupan melalui interaksi dengan lingkungan.

Keluaran dari proses belajar disebut sebagai hasil belajar. Hasil belajar artinya adalah perubahan perilaku pada individu atau pelajar sebagai akibat dari proses pembelajaran. Proses pembelajaran mengusahakan adanya perubahan perilaku tersebut guna tercapainya tujuan 
pendidikan. Salah satu hasil belajar adalah adanya perubahan atau perkembangan psikis yang lebih baik jika dibandingkan dengan sebelum proses belajar (Majid, 2014).

\section{METODE}

Penelitian ini adalah lanjutan dari penelitian mengenai pengembangan buku Manajemen Arsip Perguruan Tinggi. Ekperimen kuasi dipilih sebagai metode dalam penelitian ini. Eksperimen kuasi merupakan aktivitas percobaan untuk mendapatkan informasi dengan keadaan tidak memmungkinkan memberikan kontrol atau manipulasi untuk semua variabel yang relevan ( Nazir, 2003). Mahasiswa Program Studi Administrasi Perkantoran yang mengikuti mata kuliah Manajemen Kearsipan berjumlah 31 orang merupakan sampel dalam penelitian ini. Kompetensi dasar saat melakukan ekperimen adalah pengeloaan arsip aktif dan pengelolaan arsip inaktif. Buku yang digunakan dalam pembelajaran kearsipan adalah Buku Manajemen Arsip Pergutuan Tinggi hasil rancangan peneliti yang membahas materi tentang: (1) Konsep dasar manajemen arsip perguruan tinggi, (2) Tata naskah dinas, (3) Klasifikasi arsip, (4) Jadwal retensi arsip, (5) Pengelolaan arsip aktif, (6) Pengelolaan arsip inaktif, (7) Pengelolaan arsip statis, (8) Pengelolaan arsip vital, (9) Penyusutan arsip. Selain itu, Buku Manajemen Arsip Perguruan Tinggi hasil rancangan dilengkapi dengan daftar klasifikasi arsip dan jadwal retensi arsip pada lampiran buku. Analisis data penelitian menggunakan uji - $\mathrm{t}$ untuk dua kelompok dari data satu kelompok sampel berpasangan dengan cara melakukan perbandingan data sebelum dan sesudah adanya perlakuan dari satu kelompok sampel (Supardi, 2013).

\section{HASIL DAN PEMBAHASAN}

Penelitian ini membahas tentang pengaruh penggunaan Buku Manajemen Arsip Perguruan Tinggi terhadap hasil belajar mahasiswa Program Studi Administrasi Perkantoran yang sedang mengikuti mata kuliah Manajemen Kearsipan.

\section{Uji Asumsi Klasik}

Sebelum melakukan analisis data, dilakukan uji normalitas sebagai prasyarat melakukan Uji Paired T test. Dari hasil uji Shapiro-Wilk, didapatkan nilai Sig. pada pretest sebesar 0,241. Nilai ini lebih besar dari 0,05. Hasil ini menunjukkan bahwa nilai pretest berdistribusi normal. Demikian juga dengan posttest yang bernilai Sig 0,184. Nilai tersebut lebih besar dari 0,05. Artinya, nilai 
posttest berdistribusi normal dan analisis data dapat dilanjutkan dengan melihat hasil Uji Paired T test. Tabel 1 di bawah menunjukkan uji normalitas yang dilakukan.

Tabel 1. Uji Normalitas

\begin{tabular}{|l|r|r|r|r|r|r|}
\hline \multicolumn{1}{|c|}{ Tests of Normality } \\
\hline & \multicolumn{3}{|c|}{ Kolmogorov-Smirnov } & \multicolumn{3}{c|}{ Shapiro-Wilk } \\
\cline { 2 - 8 } & Statistic & df & \multicolumn{1}{c|}{ Sig. } & Statistic & \multicolumn{1}{c|}{ df } & \multicolumn{1}{c|}{ Sig. } \\
\hline Pretest & .085 & 31 & $.200^{*}$ & .957 & 31 & .241 \\
\hline Posttest & .183 & 31 & .010 & .953 & 31 & .184 \\
\hline *. This is a lower bound of the true significance. \\
a. Lilliefors Significance Correction \\
\hline
\end{tabular}

\section{Uji Paired T test}

Eksperimen dilakukan terhadap 31 orang mahasiswa Program studi Administrasi Perkantoran, Jurusan Ekonomi Fakultas Ekonomi, Universitas Negeri Medan, yang mengikuti mata kuliah Manajemen Kearsipan. Pada eksperimen ini digunakan Buku untuk melihat hasil ekperimen. Buku yang digunakan oleh mahasiswa dalam pembelajaran adalah buku Manajemen Arsip Perguruan Tinggi hasil rancangan peneliti. Dari hasil eksperimen, dapat diketahui bahwa hasil belajar mahasiswa setelah mengikuti pembelajaran dan menggunakan buku rancangan sebagai sumber belajar mengalami kenaikan. Hasil uji Paired Sampel t-test dangan IBM SPSS Satistics 24 dapat dilihat pada tabel berikut:

Tabel 2. Hasil Uji Paired Sample t-test

\begin{tabular}{|l|l|r|r|r|r|}
\hline \multicolumn{7}{|c|}{ Paired Samples Statistics } \\
\hline \multirow{2}{*}{ Pair 1 } & Mean & N & Std. Deviation & Std. Error Mean \\
\cline { 2 - 6 } & Pretest & 50.7742 & 31 & 13.51717 & 2.42776 \\
\cline { 2 - 6 } & Posttest & 83.3548 & 31 & 8.04383 & 1.44471 \\
\hline
\end{tabular}

Output di atas menunjukkan hasil descriptive statistic dari kedua sampel, yaitu nilai Pretest dan Posttest. Perolahan nilai rata-rata (mean) pretest hasil belajar kearsipan adalah 50,77. Nilai sebaran data (std. Deviation) adalah 13,51 dan standar error sebesar 2,43. Perolehan nilai rata-rata posttest hasil belajar arsip setelah menggunakan buku hasil rancangan adalah 83,35 dengan standar 
deviasi sebesar 8,04 dengan standar error sebesar 1,44. Hasil analisis data diatas menunjukkan bahwa rata-rata hasil belajar kearsipan mahasiswa semakin meningkat setelah menggunakan Buku Manajemen Arsip Perguruan Tinggi. Standar deviasi juga semakin mengecil dari 13,51 menjadi 8,04 yang artinya semakin kecil perbedaan mahasiswa yang memiliki nilai tinggi dan nilai rendah. Artinya, rata-rata mahasiswa dapat menguasai kompetensi tidak jauh berbeda antara mahasiswa yang pintar dan yang kurang. Sedangkan standard error yang semakin kecil pada post test semakin mengindikasikan bahwa sampling penelitian ini cukup mewakili populasi. Hasil analisis data juga menunjukkan bahwa rata-rata hasil belajar pada pretest sebesar 50,77, lebih kecil dari hasil posttest

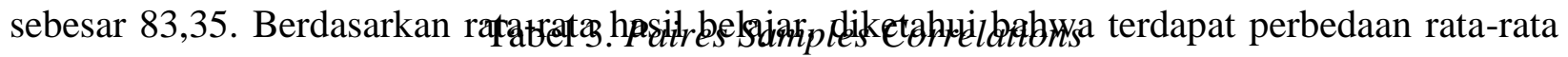
hasil belajar antara pretest dan hasil posttest. Rata-rata hasil belajar naik sebesar 27,58 point. Lebih lanjut, untuk memastikan apakah perbedaan tersebut signifikan atau tidak, hasilnya dapat dilihat dari hasil uji paired sample t test pada tabel 3.

\begin{tabular}{|c|c|c|c|c|}
\hline \multicolumn{5}{|c|}{ Paired Samples Correlations } \\
\hline & & $\mathrm{N}$ & Correlation & Sig. \\
\hline Pair 1 & Pretest \& Posttest & 31 & .476 & .007 \\
\hline
\end{tabular}

Berdasarkan table 3 di atas, korelasi antara dua variable adalah sebesar 0,476 dengan probabilitas mencapai 0,007. Karena probabilitas bernilai kurang dari 0,05, maka Ho ditolak. Artinya, rata-rata hasil belajar pretest dan posttest tidak sama atau berbeda nyata. Oleh karena itu, dapat disimpulkan bahwa terdapat perbedaan hasil belajar kearsipan sebelum menggunakan Buku Manajemen Arsip Perguruan Tinggi dengan setelah menggunakan Buku Manajemen Arsip Perguruan Tinggi untuk kompetensi dasar pengelolaan arsip Aktif dan Inaktif (arsip dinamis).

Tabel 4. Uji Paired Sample t-test

\begin{tabular}{|c|c|c|c|c|c|c|c|c|c|}
\hline \multicolumn{10}{|c|}{ Paired Samples Test } \\
\hline & & \multicolumn{5}{|c|}{ Paired Differences } & $\mathrm{t}$ & df & $\begin{array}{l}\text { Sig. (2- } \\
\text { tailed) }\end{array}$ \\
\hline & & \multirow[b]{2}{*}{ Mean } & \multirow{2}{*}{$\begin{array}{c}\text { Std. } \\
\text { Deviation }\end{array}$} & \multirow{2}{*}{$\begin{array}{l}\text { Std. Error } \\
\text { Mean }\end{array}$} & \multicolumn{2}{|c|}{$\begin{array}{c}95 \% \text { Confidence Interval } \\
\text { of the Difference }\end{array}$} & & & \\
\hline & & & & & Lower & Upper & & & \\
\hline $\begin{array}{l}\text { Pair } \\
1\end{array}$ & $\begin{array}{l}\text { Pretest - } \\
\text { Posttest }\end{array}$ & -32.58065 & 11.99659 & 2.15465 & -36.98103 & -28.18026 & -15.121 & 30 & .000 \\
\hline
\end{tabular}


Santoso (2014) mengatakan bahwa kaidah dalam pengambilan keputusan dengan uji paired sample t-test dilihat dari nilai signifikansi (Siq) hasil output SPSS, adalah sebagai berikut:

1. Apabila nilai Siq. $(2$ - tailed $)$ hasilnya kurang dari 0,05, maka Ho ditolak dan Ha diterima.

2. Apabila nilai Siq. (2-tailed) hasilnya lebih besar 0,05, maka Ho diterima dan Ha ditolak.

Hasil $t$ hitung adalah sebesar 15,121, sedangkan $t$ table menunjukkan angka 2,042. Dapat

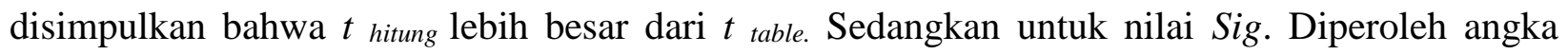
sebesar 0,000, lebih kecil dari 0,05. Artinya, Ho ditolak dan Ha diterima. Kesimpulan yang dapat diperoleh dari hasil uji adalah ada pengaruh penggunaan Buku Manajemen Arsip Perguruan Tinggi terhadap hasil belajar kearsipan pada mahasiswa Administrasi Perkantoran, Jurusan Ekonomi, Fakultas Ekonomi, Universitas Negeri Medan.

Dari hasil wawancara yang dilakukan kepada responden, dapat diketahui kompetensi pengelolaan arsip aktif dan inaktif akan lebih mudah ketika buku teks yang digunakan dalam pembelajaran berisikan konsep dan prosedur melakukan pengelolaan arsip aktif dan inaktif. Selain itu, daftar klasifikasi arsip yang ada pada lampiran Buku Manajemen Arsip Perguruan Tinggi akan sangat membantu mahasiswa ketika menentukan indeks simpan suatu berkas. Gambar dan contohcontoh melakukan pengelolaan arsip juga dapat mempermudah mahasiswa dalam melakukan proses pengelolaan arsip sejak suatu berkas diciptakan atau diterima sampai di simpan. Selain itu, lampiran jadwal rentensi arsip membantu mahasiswa memahami seberapa lama suatu berkas harus disimpan, dipindahkan, atau dimusnahkan.

\section{KESIMPULAN}

Kearsipan adalah aktivitas berupa mengelola berkas dari diterima atau diciptakan sampai dengan tahap disimpan yang bertujuan agar arsip dapat terhindar dari kerusakan dan kehilangan sehingga akan mudah ditemukan kembali jika dibutuhkan. Pengelolaan arsip aktif dan inaktif membutuhakan empat perangkat arsip, yaitu: tata naskah dinas, klasifikasi arsip, jadwal retensi arsip, serta sistem klasifikasi keamanan dan akses arsip. Sedangkan untuk mata kuliah manajemen arsip, dapat diartikan sebagai mata kuliah yang mempelajarai pengelolaan arsip aktif dan inaktif dalam suatu instansi. Mahasiswa belajar manajemen arsip melalui informasi yang diberikan oleh dosen dan dari Buku Manajemen Arsip Perguruan Tinggi. Hasil penelitian ini menunjukkan bahwa penggunaan Buku Manajemen Arsip Perguruan Tinggi memberikan efek terhadap hasil 
belajar kearsipan Mahasiswa Administrasi Perkantoran, Jurusan Ekonomi, Fakultas Ekonomi, Universitas Negeri Medan. Hasil wawancara dengan responden menunjukkan bahwa kemampuan melakukan pengelolaan arsip akan lebih mudah ketika buku yang digunakan berisikan konsep dan prosedur melaksanakan pengelolaan arsip serta adanya panduan dalam melakukan klasifikasi dan retensi arsip.

\section{DAFTAR PUSTAKA}

Abdul Majid. (2014). Penilaian Autentik Proses dan Hasil Belajar. Bandung: Rosda Karya

Nazir, M. (2003). Metode Penelitian. Jakarta: Ghalia Indonesia.

Riasmiati, A. (2016). Manajemen Kearsipan. Khazanah: Jurnal Pengembangan Kearsipan. https://doi.org/10.22146/khazanah.22880

Rusman. (2014). Model-model Pembelajaran. Jakarta: Raja Grafindo Persada.

Undang-Undang No 43 Tahun 2009

Sedarmayanti. (2003). Tata Kearsipan dengan Memanfaatkan Teknologi Modern. Bandung: Mandar Maju

Setyawan, H. (2016). Lembaga Kearsipan Perguruan Tinggi, Upaya Institusi Menjawab Tantangan Zaman. Khazanah: Jurnal Pengembangan Kearsipan. https://doi.org/10.22146/khazanah.22943

Santoso, Singgih .2014. SPSS 22 From Essential to Ekspert Skills. Jakarta: Gramedia Slameto. (2010). Belajar dan Faktor-faktor yang mempengaruhinya. Jakarta: Rineka Cipta

Supardi. (2013). Aplikasi Statistik dalam Penelitian Konsep Statistika yang Lebih Komprehensif. Jakarta: Chage Publication

Suprastiwi, Z. A., Chandrayanti, I., Azmi, Agustiani, R., \& Widayanti, T. S. (2016). Jurnal kearsipan. Jurnal Kearsipan, 11, 1-135.

Suyono. (2011). Belajar dan Pembelajaran Teori dan Konsep. Bandung: PT Remaja Rosdakarya. Trianto Ibnu Badar al-Tabany. (2014). Mendesain Model Pembelajaran Inovatif, Progresif, dan Kontekstuall. Jakarta: Prenadamedia Grup. 